\title{
Incorporating heterogeneity into growth analyses of wild and captive broadnose sevengill sharks Notorynchus cepedianus
}

\author{
J. Matias Braccini1 ${ }^{1,2,}$, Vladimir S. Troynikov ${ }^{3}$, Terence I. Walker ${ }^{2,3}$, \\ Henry F. Mollet ${ }^{4,5}$, David A. Ebert ${ }^{5,6}$, Adam Barnett ${ }^{7,8}$, Nicholas Kirby ${ }^{9}$ \\ ${ }^{1}$ Fisheries Centre, University of British Columbia, Vancouver, British Columbia V6T1Z4, Canada \\ ${ }^{2}$ Department of Zoology, University of Melbourne, Parkville, Victoria 3052, Australia \\ ${ }^{3}$ Marine and Freshwater Fisheries Research Institute, Fisheries Victoria, Department of Primary Industries, PO Box 114, \\ Queenscliff, Victoria 3225, Australia \\ ${ }^{4}$ Monterey Bay Aquarium, 886 Cannery Row, Monterey, California 93940, USA \\ ${ }^{5}$ Pacific Shark Research Center, Moss Landing Marine Laboratories, 8272 Moss Landing Road, Moss Landing, \\ California 95039, USA \\ ${ }^{6}$ South African Institute for Aquatic Biodiversity, Private Bag 1015, Grahamstown 6140, South Africa \\ ${ }^{7}$ TAFI Marine Research Laboratories, Private Bag 49, Hobart, Tasmania 7001, Australia \\ ${ }^{8}$ CSIRO Marine and Atmospheric Research, PO Box 1538, Hobart, Tasmania 7001, Australia \\ ${ }^{9}$ Curatorial Department, Melbourne Aquarium, King St., Melbourne, Victoria 3000, Australia
}

\begin{abstract}
Growth estimates for shark species are mostly derived from length-at-age data, where age information is commonly obtained from hard structures such as vertebrae and dorsal-fin spines. Unfortunately, hard structures cannot be used for estimating the age of many shark species, particularly those occurring in deep water or belonging to ancient groups. Alternative methods are therefore required for the estimation of growth for these shark groups. The broadnose sevengill shark Notorynchus cepedianus has very poorly calcified vertebrae that cannot be used for age and growth estimations. Three stochastic versions of the von Bertalanffy-Fabens growth model with random parameter $k$ were fitted to lengthincrement data of captive and of wild tagged and recaptured $N$. cepedianus from southeastern Australia, California and southern Africa. The model based on a gamma distributed parameter $k$ provided the best fit to the data. Captive females and wild females showed the highest and lowest values of mathematical expectation $\mathrm{E}[k]$, whereas wild males and wild females showed the lowest and highest values of mean maximum length $L_{\infty}$, respectively. For a time interval of $1 \mathrm{yr}$, captive females had the highest length increment, whereas wild females had the lowest length increment. Our approach allows accounting for the natural heterogeneity of growth in the estimation of the growth parameters of $N$. cepedianus, which has not been done previously for captive and wild sharks. This the first study to provide a representative set of growth parameters for male and female N. cepedianus, which is crucial information for the modelling of the population dynamics of this top predator.
\end{abstract}

KEY WORDS: Growth heterogeneity · Notorynchus cepedianus - Stochastic model · Phenotypic plasticity Resale or republication not permitted without written consent of the publisher

\section{INTRODUCTION}

Information on growth of a species is required for modelling its population dynamics, thus allowing for improved assessment of population status and facilitat- ing the development of appropriate conservation and management. Growth estimates of marine teleost and invertebrate species are commonly derived from length-at-age data, from length-increment data of tag release-recapture experiments under field and captive 
conditions, and from analysis of length frequency data (Punt et al. 2006). By contrast, growth estimates for shark species are almost exclusively derived from length-at-age data. Information on the age of sharks is obtained from counting growth-increment bands visible in the mineralised tissues of hard structures such as vertebrae (e.g. most species of the orders Lamniformes and Carcharhiniformes) and dorsal-fin spines (e.g. many species of the orders Squaliformes and Heterodontiformes; Clement 1992, Cailliet \& Goldman 2004). Unfortunately, hard structures cannot be used for estimating the age of many shark species, particularly for those species occurring in deep water or belonging to ancient groups (e.g. Hexanchiformes), where the vertebrae are poorly calcified and growth-increment bands are not apparent (Cailliet 1990, but see McFarlane et al. 2002). Alternative methods for studying growth are therefore required for these species.

The ancient shark order Hexanchiformes is composed of species with poorly calcified vertebrae (Ebert 1986, 1990, Frentzel-Beyme \& Köster 2002) and no dorsal-fin spines. McFarlane et al. (2002) reported the use of vertebral neural arches as a potential structure for age estimation of the bluntnose sixgill shark Hexanchus griseus. These authors found bands laid on neural arch sections after staining this structure with silver nitrate. However, the banding pattern was discontinuous along the whole neural arch perimeter and was only observed on the outer portion of the arches. The reliability of this methodology to estimate the age of Hexanchiformes is therefore uncertain, and further research is needed to produce growth estimates for this shark order.

The broadnose sevengill shark Notorynchus cepedianus is a top predator with a worldwide distribution in most nearshore temperate seas in waters typically no deeper than $200 \mathrm{~m}$, although larger individuals can range into deeper waters offshore (Compagno 1984, Ebert 1986, 1989, Braccini 2008). The species is increasingly retained as bycatch of several commercial fisheries worldwide, mostly in shark gillnet fisheries (e.g. in southern Australia, Walker et al. 2005), and by recreational fishers (e.g. in southern Africa, Ebert 1996). However, N. cepedianus is classed as 'data deficient' under the IUCN Red List of Threatened Species (Fowler et al. 2005), and its global and local population status is mostly unknown. This is largely due to the combination of a general lack of fisheries data and a lack of reliable estimates of growth and other demographic parameters. It is therefore necessary to generate such information for the assessment and conservation of $N$. cepedianus populations.

As typical for the order Hexanchiformes, the poorly calcified vertebrae of Notorynchus cepedianus prevent application of standard ageing techniques, such as examination of whole or cross-sectioned vertebral centra unstained or stained with alizarin red S, cobalt nitrate or ninhydrin (Ebert 1989, J. M. Braccini unpubl.). Vertebral neural arches stained with silver nitrate showed a faint and discontinuous banding pattern (J. M. Braccini unpubl.), and age information derived from this method would therefore result in uncertain age estimates and unreliable growth parameters. The only growth estimates available for $N$. cepedianus were based on information obtained from 5 juveniles kept in the Monterey Bay Aquarium, California, USA, over a period of several years (Van Dykhuizen \& Mollet 1992). These growth estimates do not describe the growth of the wild population, because juveniles in captivity tend to grow faster than juveniles in the wild (Van Dykhuizen \& Mollet 1992), and no data on the growth of adult individuals were used when fitting the growth model to the available data. The lack of adult growth length-increment data created underestimated values of predicted mean maximum length $L_{\infty}$ particularly for females, and overestimated values of the growth coefficient $k_{\text {, }}$ as these parameters are highly inversely correlated (Francis 1988). Furthermore, Van Dykhuizen \& Mollet (1992) fitted 5 deterministic methods based on the von Bertalanffy growth model (VBGM) to the growth data. As in any deterministic approach, the standard VBGM provides average values of growth parameters, ignoring natural variation in growth among individuals.

Here we explored the use of stochastic versions of the 2-parameter von Bertalanffy-Fabens growth model (VB-FGM) for tagging data, developed by Troynikov (1998). This modelling framework explicitly recognises individual variation in growth and provides a more flexible and biologically comprehensive representation of growth. We fitted this stochastic VB-FGM to length-increment data for juvenile and adult captive and wild Notorynchus cepedianus from Australia, California and southern Africa to account for the natural heterogeneity of growth in the estimation of growth parameters for this species.

\section{MATERIALS AND METHODS}

Data. Five independent data sets were fitted to the stochastic VB-FGM. Growth data from Notorynchus cepedianus (length-at-capture, time-in-captivity, and length-at-release back into the wild) were obtained from individuals held captive in the Melbourne Aquarium, Victoria, Australia, and in the Monterey Bay Aquarium. In the Melbourne Aquarium, sharks were housed in a 550001 multispecies closed system with artificial reef lining the walls and bottom, and a $60 \% \mathrm{~h}^{-1}$ water turnover, where the average water temperature 
was $18^{\circ} \mathrm{C}$. In the Monterey Bay Aquarium, sharks were housed in a $1.25 \mathrm{Ml}$ multispecies semi-open system with artificial reef lining the walls and bottom, and a 90 min water turnover. The average water temperature fluctuated between 12 and $14^{\circ} \mathrm{C}$ (ambient Monterey Bay water temperature; Van Dykhuizen \& Mollet 1992).

Growth length-increment data from wild sharks (length at capture, time at liberty and length at recapture) were obtained through 2 tagging programs in southern Australia and 1 tagging program in southern Africa. For the first tagging program in southern Australia (Walker et al. 1997), Notorynchus cepedianus were tagged as part of the Southern Shark Tagging Project during 1990 to 1996 in offshore waters of southeastern Australia. Sharks were caught by commercial shark-fishing vessels during normal operations using either bottom-set monofilament gillnets or bottom-set longlines. Sharks hauled on board and judged to be in strong live condition were sexed, measured and tagged in the lower anterior region of the dorsal fin with either rototags (Daltons; sharks $60-100 \mathrm{~cm}$ total length, TL) or jumbo tags (Daltons; sharks $>100 \mathrm{~cm}$ $\mathrm{TL})$. Data on date and location of tagging were also recorded. The majority of the recaptures were reported by commercial fishers (Walker et al. 1997). The second tagging program in southern Australia was conducted in the coastal regions of southeastern Tasmania. $N$. cepedianus were sampled seasonally from December 2006 to February 2009 using fishery-independent bottom-set longlines. Upon hauling the longline, sharks were brought onboard, and TL and precaudal length were measured. Sharks were sexed and tagged in the dorsal fin with plastic jumbo tags. All recaptures occurred on subsequent research trips, and the sharks were re-measured by the same researchers. For the tagging program in southern Africa (Ebert 1996), $N$. cepedianus were tagged as part of the Oceanographic Research Institute's national tagging program. Sharks were tagged with rototags during beach angling competitions between East London, Eastern Cape Province, South Africa, and northern Namibia. Upon capture, sharks were measured for TL and precaudal length. Although anglers were asked to record sex, in most instances this variable was not taken. Recaptures were obtained from anglers who either saved the tag or recorded the number and released the shark. Anglers usually filled out a card with the pertinent information and returned it to the Oceanographic Research Institute's national tagging program.

In general, length information was recorded as TL and measured in natural position as a straight line from the snout to the tip of the tail to the nearest $\mathrm{cm}$, except for sharks held in the Monterey Bay Aquarium, where length was recorded over the curve of the body surface.
These data were transformed to TL using the conversion factor 0.961 reported by Van Dykhuizen \& Mollet (1992). Table 1 lists the number of released (captive) and recaptured (wild) Notorynchus cepedianus from

Table 1. Notorynchus cepedianus. Summary of data used in the modelling of shark growth. $L_{\mathrm{o}}$, initial length $L_{\mathrm{f}}$, lengthat-recapture (wild animals) or length-at-release (captive animals). M: male, F: female; U: unknown. Southeastern Australia 1, 2: first and second tagging programs, respectively

\begin{tabular}{|c|c|c|c|c|}
\hline Data set & Sex & $\begin{array}{c}L_{0} \\
(\mathrm{~cm})\end{array}$ & $\begin{array}{c}L_{\mathrm{f}} \\
(\mathrm{cm})\end{array}$ & $\begin{array}{c}\text { Days in captivity/ } \\
\text { at liberty }\end{array}$ \\
\hline $\begin{array}{l}\text { Southeastern } \\
\text { Australia } 1\end{array}$ & $\begin{array}{c}M \\
F \\
U \\
M \\
U \\
M\end{array}$ & $\begin{array}{l}200 \\
101 \\
72 \\
60 \\
70 \\
67\end{array}$ & $\begin{array}{c}204 \\
158 \\
115 \\
105 \\
91 \\
69\end{array}$ & $\begin{array}{c}422 \\
1061 \\
118 \\
327 \\
278 \\
60\end{array}$ \\
\hline $\begin{array}{l}\text { Southeastern } \\
\text { Australia } 2\end{array}$ & $\begin{array}{c}M \\
F \\
F \\
M \\
F \\
F \\
F \\
M \\
M \\
F \\
F \\
M \\
M \\
F \\
M \\
F \\
F \\
F \\
F \\
F \\
F \\
F \\
F \\
F \\
F \\
F \\
M\end{array}$ & $\begin{array}{c}220 \\
235 \\
194 \\
215 \\
232 \\
223 \\
247 \\
227 \\
221 \\
234 \\
284 \\
195 \\
158 \\
246 \\
167 \\
226 \\
198 \\
147 \\
223 \\
207 \\
247 \\
150 \\
235 \\
218 \\
210 \\
52 \\
200\end{array}$ & $\begin{array}{c}246 \\
270 \\
201 \\
222 \\
236 \\
234 \\
252 \\
229 \\
231 \\
241 \\
288 \\
204 \\
164 \\
255 \\
175 \\
228 \\
199 \\
149 \\
225 \\
211 \\
248 \\
170 \\
245 \\
222 \\
225 \\
67 \\
204\end{array}$ & $\begin{array}{c}1446 \\
850 \\
715 \\
417 \\
405 \\
399 \\
379 \\
373 \\
366 \\
327 \\
279 \\
272 \\
267 \\
248 \\
214 \\
212 \\
129 \\
126 \\
126 \\
114 \\
45 \\
345 \\
378 \\
345 \\
366 \\
121 \\
422\end{array}$ \\
\hline Southern Africa & $\begin{array}{l}\mathrm{U} \\
\mathrm{U} \\
\mathrm{U} \\
\mathrm{U} \\
\mathrm{U}\end{array}$ & $\begin{array}{c}134 \\
116 \\
76 \\
100 \\
106\end{array}$ & $\begin{array}{c}137 \\
118 \\
80 \\
141 \\
107\end{array}$ & $\begin{array}{l}129 \\
271 \\
367 \\
396 \\
135\end{array}$ \\
\hline $\begin{array}{l}\text { Melbourne } \\
\text { Aquarium }\end{array}$ & $\begin{array}{l}\mathrm{F} \\
\mathrm{M} \\
\mathrm{F} \\
\mathrm{F} \\
\mathrm{F} \\
\mathrm{F} \\
\mathrm{F} \\
\mathrm{F} \\
\mathrm{F}\end{array}$ & $\begin{array}{c}53 \\
48 \\
48 \\
63 \\
92 \\
185 \\
220 \\
240 \\
178\end{array}$ & $\begin{array}{c}68 \\
57 \\
54 \\
144 \\
104 \\
240 \\
256 \\
261 \\
210\end{array}$ & $\begin{array}{c}74 \\
42 \\
29 \\
821 \\
116 \\
2011 \\
784 \\
1700 \\
324\end{array}$ \\
\hline $\begin{array}{l}\text { Monterey Bay } \\
\text { Aquarium }\end{array}$ & $\begin{array}{l}\mathrm{F} \\
\mathrm{M} \\
\mathrm{F} \\
\mathrm{F} \\
\mathrm{F}\end{array}$ & $\begin{array}{c}115 \\
94 \\
83 \\
70 \\
62\end{array}$ & $\begin{array}{l}177 \\
181 \\
143 \\
149 \\
136\end{array}$ & $\begin{array}{l}1771 \\
1771 \\
1771 \\
1073 \\
1073\end{array}$ \\
\hline
\end{tabular}


each of the 5 data sets used for modelling growth. Data used in the modelling included only those individuals for which information was available on time-in-captivity or time-at-liberty, length-at-capture and length-atrelease from captivity or length-at-recapture.

Most of the data sets had small sample sizes ( $\mathrm{n}<10$; Table 1). Based on so few samples, growth parameters derived for males and females from each individual data set would not be biologically representative. For example, captive individuals in the Melbourne and Monterey Bay Aquaria were mostly females, so male growth estimates derived from these data sets would be based on only 2 individuals. Therefore, no attempt was made to fit the model to each sex of the individual data sets for a comparative analysis of growth. Instead, the model was fitted to selected data sets. For comparing growth of captive and wild individuals, data from the 2 aquaria were combined despite differences in water temperatures. Females kept in captivity and females tagged and recaptured in the wild (data from the 3 tagging programs combined) had comparable distributions of TL (Kolmogorov-Smirnov test, $d_{\mathrm{MAX}}=$ $0.633, \mathrm{p}>0.001)$ and days-at-liberty or days-in-captivity $\left(d_{\text {MAX }}=0.516, p>0.001\right.$; Fig. 1$)$. Hence, these 2 data sets were fitted to the model to determine differences in growth between captive and wild female animals. Wild males also had comparable TL $\left(d_{\mathrm{MAX}}=0.400, \mathrm{p}>\right.$ $0.001)$ and times-at-liberty $\left(d_{\mathrm{MAX}}=0.133, \mathrm{p}>0.001\right)$ distributions to wild females (Fig. 1). Therefore, growth parameters were also estimated for each sex. Given that differences were found between the growth parameters of captive and wild females (see Results), the estimation of growth parameters for males and females was done using data from wild animals only (all tagging programs combined).

Modelling. In this section, we consider the VB-FGM where the growth parameter $k$ is random with probability density function $(p d f) g(k)$. Consider the equation

$$
\Delta l=\left(L_{\infty}-11\right)(1-\exp (-k \Delta t)
$$

where $\Delta l$ is growth increment, $L_{\infty}$ is a growth parameter, $l 1$ is length at release and $\Delta t$ is time-at-liberty/ time-in-captivity. From Eq. (1), we have

$$
k=-\ln \left[1-\Delta l /\left(L_{\infty}-11\right)\right] / \Delta t
$$

Using a change of variable in $g(k)$, we then have a $p d f$ for $\Delta l$ conditional on 11

$$
f(\Delta l \mid l 1)=g(k) \mathrm{J}[\Delta l]
$$

where $J[\Delta l]$ is the Jacobian of transformation (2).

For a detailed description of the modelling framework and parameterisation, see Troynikov (1998) and Troynikov \& Walker (1999).

Three stochastic versions of the VB-FGM were fitted to data of Notorynchus cepedianus based on the as-
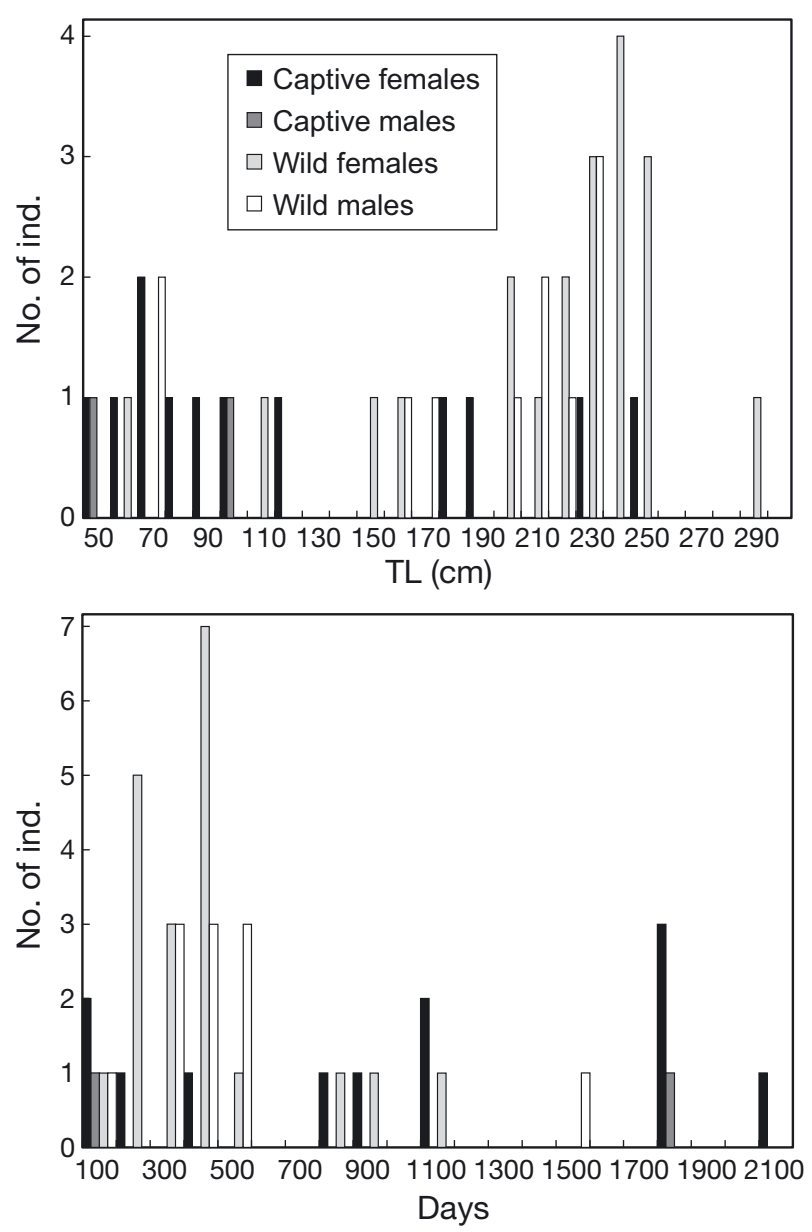

Fig. 1. Notorynchus cepedianus. Length- and days-at-liberty or days-in-captivity. TL: total length

sumption that the growth parameter $k$ varies among individuals according to 3 probability distributions: Weibull, gamma and log-normal (Troynikov \& Gorfine 1998). All 3 distributions are positive and have light, medium and heavy tails. Therefore, these distributions are biologically consistent (distinct from models that use a normal distribution, which includes negative values for the random parameter $k$ ) and provide a flexible choice when fitting growth data with different statistical properties. The mathematical expectation $\mathrm{E}[\mathrm{k}]$ and the standard deviation $\mathrm{SD}[k]$ of the growth rate $k$ were calculated for each model. Note that $\mathrm{SD}[k]$ represents population growth heterogeneity, not the statistical error of the estimate of parameter $k$ as in a deterministic approach.

Each model has the form of a $p d f_{\text {; }}$ therefore, the maximum of the likelihood function is the natural estimator for the model's parameters. Kullback-Leibler divergence $\Delta(M 1, M 2)$ was used to compare the performance of the alternative stochastic models $(\mathrm{M})$ in fitting the data (Kullback \& Leibler 1951). For example, if $\Delta(\mathrm{M} 1, \mathrm{M} 2)<0$, then model M2 fits the data better than 
Table 2. Notorynchus cepedianus. Parameter estimates of the stochastic models and the deterministic von Bertalanffy-Fabens growth model (VB-FGM). SE (\%): percentage standard error; $L_{\infty}$ : mean maximum length $(\mathrm{cm}) ; \mathrm{E}[k]$ : mathematical expectation of $k\left(\mathrm{yr}^{-1}\right) ; \mathrm{SD}[k]$ : percentage of standard deviation (representing heterogeneity in the population rather than statistical error; $\mathrm{yr}^{-1}$ ) for the stochastic models

\begin{tabular}{|c|c|c|c|c|c|c|c|}
\hline \multirow[t]{2}{*}{ Model } & \multirow[t]{2}{*}{ Parameter } & \multicolumn{2}{|c|}{ Captive females } & \multicolumn{2}{|c|}{ Wild females } & \multicolumn{2}{|c|}{ Wild males } \\
\hline & & Estimate & $\mathrm{SE}(\%)$ & Estimate & $\mathrm{SE}(\%)$ & Estimate & $\mathrm{SE}(\%)$ \\
\hline Weibull & $\begin{array}{c}L_{\infty} \\
\mathrm{E}[k] \\
\mathrm{SD}[k]\end{array}$ & $\begin{array}{c}289 \\
0.235 \\
49\end{array}$ & 117 & $\begin{array}{c}348 \\
0.087 \\
54\end{array}$ & 64 & $\begin{array}{c}272 \\
0.146 \\
56\end{array}$ & 100 \\
\hline Gamma & $\begin{array}{c}L_{\infty} \\
\mathrm{E}[k] \\
\mathrm{SD}[k]\end{array}$ & $\begin{array}{c}286 \\
0.221 \\
49\end{array}$ & 133 & $\begin{array}{c}357 \\
0.074 \\
58\end{array}$ & 77 & $\begin{array}{c}277 \\
0.123 \\
57\end{array}$ & 121 \\
\hline Log-normal & $\begin{array}{c}L_{\infty} \\
\mathrm{E}[k] \\
\mathrm{SD}[k]\end{array}$ & $\begin{array}{c}287 \\
0.243 \\
60\end{array}$ & 159 & $\begin{array}{c}386 \\
0.072 \\
72\end{array}$ & 98 & $\begin{array}{c}283 \\
0.138 \\
72\end{array}$ & 162 \\
\hline Deterministic VB-FGM & $\begin{array}{c}L_{\infty} \\
k\end{array}$ & $\begin{array}{c}289 \\
0.122\end{array}$ & $\begin{array}{l}143 \\
335\end{array}$ & $\begin{array}{c}341 \\
0.089\end{array}$ & $\begin{array}{l}415 \\
954\end{array}$ & $\begin{array}{c}251 \\
0.237\end{array}$ & $\begin{array}{l}120 \\
578\end{array}$ \\
\hline Sample size & & 12 & & 20 & & 11 & \\
\hline
\end{tabular}

model M1. Parameters were estimated using a FORTRAN computer program developed by V. Troynikov. No attempt was made to statistically compare growth parameters derived from the different data sets, because in cases of small sample sizes, likelihood ratio test may be not representative.

\section{RESULTS}

The data used in the modelling of Notorynchus cepedianus growth exhibited high heterogeneity in TL and time-at-liberty or time-in-captivity (Table 1, Fig. 1). Within each group modelled, the 3 stochastic VB-FGMs, based on Weibull, gamma and log-normal pdfs for $k$, provided similar growth parameters (Table 2). For all data sets or groups of data sets modelled, the model with gamma $p d f$ for $k$ provided the best fit to the data, followed by log-normal pdf (Table 3). Overall, the deterministic VB-FGM provided different growth parameters to the stochastic models, or when the parameter estimates were similar (E[k] for wild females), there was very high uncertainty in the estimation (Table 2).

Captive and wild females showed the highest and lowest values of $\mathrm{E}[k]$, respectively (Table 2), regardless of the model used. Wild females and wild males showed the highest and lowest values of $L_{\infty}$, respectively (Table 2), again regardless of the model used.

For initial sizes of 50, 100, 150 and $200 \mathrm{~cm}$ TL, captive females showed the highest length increments for a time interval of $1 \mathrm{yr}$ (Table 4, Fig. 2). Wild females showed the lowest length increments (Table 4, Fig. 2). For example, for a $1 \mathrm{yr}$ period, the estimated average growth increment of captive females of an initial size of $50 \mathrm{~cm}$ TL was $46 \mathrm{~cm}$, whereas for wild females of the same initial size, it was $22 \mathrm{~cm}$ (Table 4).
Table 3. Notorynchus cepedianus. Kullback-Leibler divergence values for different models

\begin{tabular}{|lrrr|}
\hline Model & $\begin{array}{r}\text { Captive } \\
\text { females }\end{array}$ & $\begin{array}{c}\text { Wild } \\
\text { females }\end{array}$ & $\begin{array}{c}\text { Wild } \\
\text { males }\end{array}$ \\
\hline Weibull vs. Gamma & -0.0548 & -0.0126 & -0.0431 \\
Weibull vs. Log-normal & -0.0286 & 0.0511 & 0.0206 \\
Gamma vs. Log-normal & 0.0262 & 0.0637 & 0.0636 \\
\hline
\end{tabular}

Table 4. Notorynchus cepedianus. Estimated (gamma k) average growth length-increment (in $\mathrm{cm}$ ) of captive females, wild females and wild males for a time interval of $1 \mathrm{yr}$ and initial sizes of 50,100,150, and $200 \mathrm{~cm}$ total length

\begin{tabular}{|lccc|}
\hline Initial size & Captive females & Wild females & Wild males \\
\hline 50 & 45.8 & 21.6 & 25.7 \\
100 & 36.1 & 18.1 & 20.1 \\
150 & 26.4 & 14.6 & 14.4 \\
200 & 16.8 & 11.1 & 8.7 \\
\hline
\end{tabular}

\section{DISCUSSION}

The data sets used in the modelling of Notorynchus cepedianus growth were highly heterogeneous. Growth and other biological attributes are heterogeneous as a result of the natural variability in a population due to genetic and environmental factors (Troynikov 1998, Tovar-Avila et al. 2009). In addition, most data sets used in our study had small sample sizes, which tend to increase apparent heterogeneity because the probability of sampling 2 individuals with similar genetics and environmental experiences, and thus growth, is small. When growth data are highly heterogeneous, a deterministic modelling approach will provide uninformative growth parameter estimates. A deterministic 

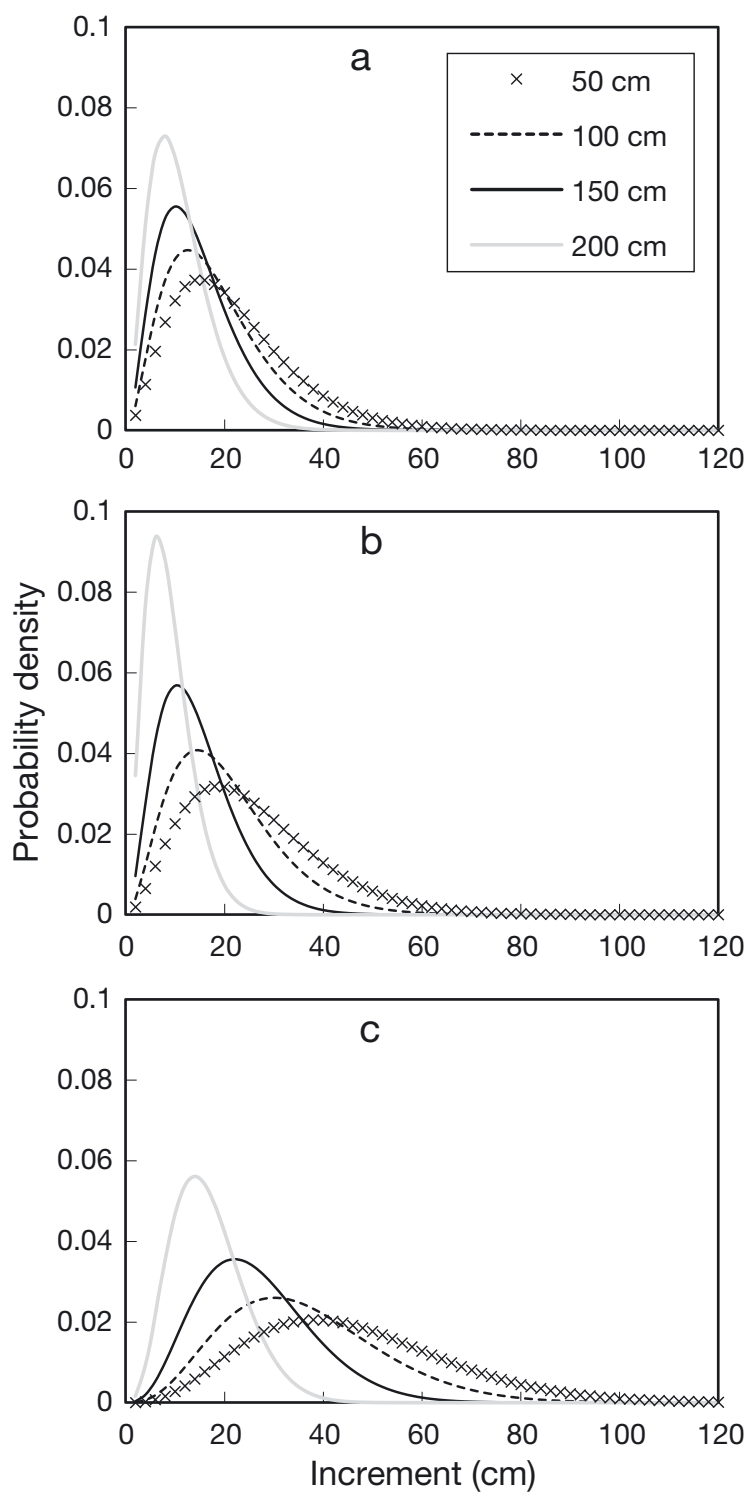

Fig. 2. Notorynchus cepedianus. Probability density (gamma $k$ ) for the length increment of (a) wild females, (b) wild males and (c) captive females for a time interval of $1 \mathrm{yr}$ and initial sizes of $50,100,150$, and $200 \mathrm{~cm}$ total length

approach replaces the natural distribution of a growth parameter with a mean value for the whole population and affects population dynamics assessments (Troynikov 1998). A deterministic approach should only be applied when a large part of the population has growth parameter values close to the average, i.e. when data are relatively uniform and homogeneous (Troynikov 1998). A number of studies have explicitly shown the bias in growth parameter estimation when the Fabens method was used (e.g. Chien \& Condrey 1987, Francis 1988, Maller \& deBoer 1988). The main reason for biased estimation of von Bertalanffy growth parameters from tagging data is the large variation of age for any given length class. Unlike the length-at-age growth data used in the von Bertalanffy model, tag increment data provide no information about age.

Tag and recapture datasets are generally heterogeneous and contain small sample sizes, particularly for shark species. For Notorynchus cepedianus, the error in the estimation of growth parameters by the deterministic approach was very high (e.g. $>900 \%$ in the case of the $\mathrm{E}[k]$ value for wild females). Therefore, there is high uncertainty in the growth parameter values estimated by the deterministic approach. In contrast, the uncertainty around the growth parameter estimates using the stochastic approach was much lower (SD $<60 \%$ for the gamma pdf), indicating that the stochastic approach captured the heterogeneity in the data and provided more informative estimates of the growth parameter $k$. Field observations support the stochastic model predictions. The $L_{\infty}$ estimates for wild males (272-283 cm TL) are similar to the maximum reported size for males (242 cm TL, Ebert 1990) and, although the $L_{\infty}$ estimates for wild females (348-86 cm TL) are higher than the maximum reported size for the species ( 300 cm TL, Last \& Stevens 1994), there is building evidence, provided mostly by commercial and recreational fishers, that female $N$. cepedianus can reach maximum sizes in excess of $300 \mathrm{~cm}$ (J. Braccini unpublished). Furthermore, neonate cohort groups of $N$. cepedianus (unspecified sex) grow from a size-atbirth of 35-55 cm TL to 70-80 cm TL during their first season (D. A. Ebert unpubl.). This represents an increase of 25-35 cm TL for neonates during their first year of life. For $50 \mathrm{~cm}$ TL sharks during a 1 yr period, the stochastic model predicted growth length-increments of $22 \mathrm{~cm}$ for wild females and $26 \mathrm{~cm}$ for wild males, corresponding with length increments observed in the field. By explicitly recognising variation in individual growth rates, our modelling framework provided a more flexible and biologically comprehensive representation of $N$. cepedianus growth. In addition to a better representation of population growth, another advantage of the stochastic model is that the outputs can be directly incorporated into population dynamics models by calculating probabilistic growth transition matrices (Troynikov 1998, Punt et al. 2006).

Several studies have reported faster growth in captive sharks (e.g. Gruber \& Stout 1983, Natanson \& Cailliet 1990). However, these studies compared the growth of only juvenile sharks (individuals reared in captivity) to the growth of adult sharks (individuals tagged and recaptured in the wild), confounding the analyses and the interpretation of results (Carrier \& Luer 1990). In our study, the size range of female Notorynchus cepedianus was better represented for both captive and wild individuals, making the different data sets more comparable. 
Female Notorynchus cepedianus grow faster in captivity than in the wild. Van Dykhuizen \& Mollet (1992) reported no differences in the growth of captive and wild $N$. cepedianus, but this claim is based on a very limited data set. Other shark species also show an increase in growth rate of up to 2 to 3 times under certain captive-rearing conditions (Wass 1971, Taylor \& Wisner 1989). This pattern is consistent with the differences observed in the growth parameter values of captive and wild female $N$. cepedianus (Table 2), indicating a degree of plasticity in the growth of this species. To compare the growth of captive and wild individuals, we pooled growth information of sharks from different populations (Australia and southern Africa for wild sharks, and Australia and California for captive sharks). In doing this, we assumed that exogenous (environmental) factors had a much larger effect on growth than endogenous (genetic) factors. Although there is currently no information on how geographically variable the genetic structure of $N$. cepedianus is, some evidence supports our assumption. Captive sharks from the Melbourne Aquarium were taken from the same area as wild sharks tagged and recaptured in the Southern Ocean. When only these data sets were compared (not shown), the differences in the growth parameters persisted. This suggests a degree of phenotypic plasticity in the growth of $N$. cepedianus probably related to differences in feeding periodicity and water temperature, as reported for other shark species.

Our comparative study has some limitations. For the comparison of growth of captive and wild females, we merged some of the data sets to offset the small sample sizes (e.g. lack of adult growth information for the Monterey Bay Aquarium data set). In doing this, we assumed no variability in the rearing conditions of captive sharks in the 2 aquaria, and no variability in the environmental conditions of the different locations where wild sharks were tagged and recaptured. As pointed out above, Notorynchus cepedianus shows phenotypic plasticity in growth, so it is expected that different environmental and feeding conditions would translate into differences in growth. A more rigorous experimental design with larger sample sizes would allow testing for the relative contribution of these other factors.

Wild male Notorynchus cepedianus grow faster but reach smaller sizes than wild females (Ebert 1996, present study). This is the typical pattern of sexual differences in growth shown by most viviparous shark species where females tend to grow larger and more slowly than males (Cailliet \& Goldman 2004). Due to the high correlation among growth parameters, a direct comparison of parameters between species has no biological meaning (Tovar-Avila et al. 2009); however, $k$ values could be used to rank long-lived marine species in terms of risk where groups with values $<0.10$ are particularly vulnerable (Musick 1999). Under this criterion, $N$. cepedianus (particularly females) is classed as a vulnerable species. Higher values of $k$ and smaller values of $L_{\infty}$, for both male and female $N$. cepedianus, were estimated by Van Dykhuizen \& Mollet (1992). However, these estimates were based on 5 captive juveniles: 4 females and 1 male. Our study therefore provides a more representative set of growth parameters for male and female $N$. cepedianus than those estimated by Van Dykhuizen \& Mollet (1992) due to the more rigorous modelling approach and more representative data sets used. The approach demonstrates the potential for further improvement in comparative analysis of shark somatic growth when limited growth data are available.

Acknowledgements. A.B. thanks J. Yick and A. Pender and several other volunteers for field assistance, J. Stevens for access to CSIRO data sets, and Save Our Seas Foundation for their support. D.A.E. thanks NOAA/NMFS for support of the National Shark Research Consortium and Pacific Shark Research Center for their support.

\section{LITERATURE CITED}

Braccini JM (2008) Feeding ecology of two high-order predators from south-eastern Australia: the coastal broadnose and the deepwater sharpnose sevengill sharks. Mar Ecol Prog Ser 371:273-284

Cailliet GM (1990) Elasmobranch age determination and verification: an updated review. In: Pratt HL Jr, Gruber SH, Taniuchi $\mathrm{T}$ (eds) Elasmobranchs as living resources: advances in biology, ecology, systematics, and the status of the fisheries. NOAA Tech Rep NMFS 90, Honolulu, HI, p 157-165

Cailliet GM, Goldman KJ (2004) Age determination and validation in chondrichthyan fishes. In: Carrier JF, Musick JA, Heithaus MR (eds) The biology of sharks and their relatives. CRC Press, Boca Raton, FL, p 399-447

Carrier JC, Luer CA (1990) Growth rates in the nurse shark, Ginglymostoma cirratum. Copeia 1990:686-692

Chien YH, Condrey RE (1987) Bias in estimating growth parameters using Faben's mark-recapture procedures. Asian Fish Sci 1:65-74

Clement JG (1992) Re-examination of the fine structure of endoskeletal mineralization in Chondrichthyans: implications for growth, ageing and calcium homeostasis. Aust J Mar Freshw Res 43:157-181

Compagno LJV (1984) FAO species catalogue. Sharks of the world. An annotated and illustrated catalogue of shark species known to date. (1) Hexanchiformes to Lamniformes. Vol 4. FAO Fisheries Synopsis, FAO, Rome

Ebert DA (1986) Aspects of the biology of hexanchid sharks along the California coast. In: Uyeno T, Arai R, Taniuchi T, Matsuura K (eds) Indo-Pacific fish biology. Proc 2nd Int Conf Indo-Pacific Fish. Ichthyological Society of Japan, Tokyo, p 437-449

Ebert DA (1989) Life history of the sevengill shark, Notorynchus cepedianus Peron 1807, in two Northern California Bays. Calif Fish Game 75:101-112

Ebert DA (1990) The taxonomy, biogeography, and biology of 
cow and frilled sharks (Chondrichthyes: Hexanchiformes). $\mathrm{PhD}$ thesis, Rhodes University, Grahamstown

Ebert DA (1996) Biology of the sevengill shark Notorynchus cepedianus (Peron, 1807) in the temperate coastal waters of Southern Africa. S Afr J Mar Sci 17:93-103

Fowler S, Cavanagh RD, Camhi M, Burgess GH and others (2005) Sharks, rays and chimaeras: the status of the chondrichthyan fishes. IUCN Species Survival Commission, Shark Specialist Group, IUCN, Gland

Francis RICC (1988) Maximum likelihood estimation of growth and growth variability from tagging data. NZ J Mar Freshw Res 22:42-51

Frentzel-Beyme BZ, Köster FW (2002) On the biology of the sharpnose sevengill shark, Heptranchias perlo, from the Great Meteor Seamount (central eastern Atlantic). In: Vacchi M, La Mesa G, Serena F, Seret B (eds) 4th Eur Elasmobranch Assoc Meet 2000. Societé française d'Ichtyologie SFI, Livorno, p 77-96

Gruber SH, Stout RG (1983) Biological materials for the study of age and growth in a tropical marine elasmobranch, the lemon shark, Negaprion brevirostris (Poey). NOAA Tech Rep NMFS Circular 8

Kullback S, Leibler RA (1951) On information and sufficiency. Ann Math Stat 22:79-86

Last PR, Stevens JD (1994) Sharks and rays of Australia. CSIRO Publishing, Melbourne

Maller RA, deBoer ES (1988) An analysis of two methods of fitting the von Bertalanffy curve to capture-recapture data. Aust J Mar Freshw Res 39:459-466

McFarlane GA, King JR, Saunders MW (2002) Preliminary study on the use of neural arches in the age determination of bluntnose sixgill sharks (Hexanchus griseus). Fish Bull 100:861-864

Musick JA (1999) Ecology and conservation of long-lived marine animals. Am Fish Soc Symp 23:1-10

Natanson LJ, Cailliet GM (1990) Vertebral growth zone deposition in Pacific angel sharks. Copeia 1990:1133-1145

Editorial responsibility: Hans Heinrich Janssen, Oldendorf/Luhe, Germany
Punt AE, Hobday D, Gerhard J, Troynikov VS (2006) Modelling growth of rock lobsters, Jasus edwardsii, off Victoria, Australia using models that allow for individual variation in growth parameters. Fish Res 82:119-130

Taylor L, Wisner M (1989) Growth of captive blacktip reef sharks (Carcharhinus melanopterus). Bull Inst Océanogr (Monaco) 5:211-217

Tovar-Avila J, Troynikov VS, Walker TI, Day RW (2009) Use of stochastic models to estimate the growth of the Port Jackson shark, Heterodontus portusjacksoni, off eastern Victoria, Australia. Fish Res 95:230-235

> Troynikov VS (1998) Probability density functions useful for parameterization of heterogeneity in growth and allometry function. Bull Math Biol 60:1099-1122

Troynikov VS, Gorfine HK (1998) Alternative approach for establishing legal minimum lengths for abalone based on stochastic growth models for length increment data. J Shellfish Res 17:827-831

Troynikov VS, Walker TI (1999) Vertebral size-at-age heterogeneity in gummy shark harvested off southern Australia. J Fish Biol 54:863-877

> Van Dykhuizen G, Mollet HF (1992) Growth, age estimation and feeding of captive sevengill sharks, Notorynchus cepedianus, at the Monterey Bay Aquarium. Aust J Mar Freshw Res 43:297-318

Walker TI, Brown LP, Bridge NF (1997) Southern shark tagging project. Report 93/066. Final Report to Fisheries Research and Development Corporation Marine and Freshwater Resources Institute, Queenscliff

Walker TI, Hudson RJ, Gason AS (2005) Catch evaluation of target, by-product and by-catch species taken by gillnets and longlines in the shark fishery of south-eastern Australia. J Northwest Atl Fish Sci 35:505-530

Wass RC (1971) A comparative study of the life history, distribution, and ecology of the sandbar shark and the grey reef shark in Hawaii. PhD thesis, University of Hawaii, Honolulu

Submitted: August 17, 2009; Accepted: March 15, 2010 Proofs received from author(s): April 15, 2010 